\title{
Bilateral Mandibular Posterior Edentulous Rehabilitation for Unstable Occlusion Patient with Bilateral Attachment Retained Mandibular Removable Partial Denture
}

\author{
Cindy Karina Hartono, Nike Hendrijantini and Soekobagiono \\ Department of Prosthodontic, Faculty of Dental Medicine, Universitas Airlangga, Surabaya, Indonesia
}

\begin{abstract}
A 62-year-old female patient came to the Dental Hospital of Universitas Airlangga to maintain her remaining teeth and make dentures for the missing teeth, and expressed that she expected a high aesthetic result. The patient had lost bilateral posterior mandibular teeth, resulting in unstable occlusion. To stabilize the occlusion, this patient was treated by temporary denture. After 3 months of follow up and confirmed adaptation with the new occlusion, prosthodontic treatment was done consisting of bilateral attachment retained mandibular removable partial denture, aimed at the patient's expectation of acquiring good aesthetic results and functional rehabilitation.
\end{abstract}

Key Words: removable partial denture, dental occlusion, prosthodontics, aesthetics

\section{INTRODUCTION}

Tooth loss is a physical defect that is related to the functional, social and mental state of on an individual, as well as for the aesthetics concerns. The mental effects of various forms of loss involving body organs have been documented in the literature and are recognized to have profound consequences for these individuals. Affection is also directed at the emotional consequences of total and partial loss of teeth with various consequences, including feeling of mourning, loss of self-confidence, anxiety about appearance and selfimage, protecting the secret of losing teeth, and observing taboo material that cannot be discussed with people. ${ }^{1}$

Tooth loss can create an unstable occlusion. The capability to mark occlusal instability and to achieve occlusal stability should be very well understood by every dentist. The way to plan treatment ends is to have stable results that do not give birth or preserve damage to the stomatognathic system. ${ }^{2}$

Posterior tooth loss accompanied by advanced occlusion further reduces the number of occlusion pairs present to function. The loss of posterior chewing function results in the

Paper presented at the Joint Scientific Meeting in Special Care Dentistry, July 5, 2019, Amerta Room, 4th Floor, main campus of Universitas Airlangga, Surabaya, Indonesia.

Corresponding author: Nike Hendrijantini Department of Prosthodontic Faculty of Dental Medicine Universitas Airlangga J. Mayjen. Prof. Dr. Moestopo No. 47 Surabaya 60132 - Indonesia Email: nike-h@fkg.unair.ac.id patient tending to use anterior teeth to replace its function. This result in instability of the occlusion and the patient tends to advance the chin and change the occlusions to compensate for this. ${ }^{3}$

The use of transitional dentures can be an option to overcome instability in occlusion. The form of this transitional prosthesis has the following indications: for restoring the occlusal plane when losing premolar and molar teeth; 
before treatment in other fields (orthopaedic surgery) with the aim of occlusal stabilization and muscle conditioning; return of Vertical Dimension of Occlusion (VDO), as well as a guide for oral rehabilitation. In addition, this transitional denture is considered very applicable to the correct return of the occlusal plane by poor mandibular position when wider treatment modalities are contraindicated. ${ }^{4}$

After the occlusion is stable and evaluated, one of the treatment plans chosen to restore the patient's function and aesthetics is to use precision attachments denture. In this case, the patient had high aesthetic expectations without wanting to see clasp in the anterior teeth. Precision attachment denture has long been characterized as the most effective form of partial denture treatment. ${ }^{5}$

This study discussed a bilateral mandibular posterior edentulous rehabilitation for unstable occlusion patient with bilateral attachment retained removable partial denture to regain masticatory function, aesthetic performance, speech, and swallowing, as well as, fulfilling the patient's aesthetic expectation.

\section{CASE REPORT}

A 62-year old female patient came to the Department of Prosthodontic of the Dental Hospital of Universitas Airlangga on her own to maintain her remaining teeth, make dentures in order to eat and chew well, and to realize her expected high aesthetic result. The medical history and the general condition of the patient were unremarkable and the patient did not have any history of medical disorder. Patient had experienced using the denture since 2 years ago which was no longer used because the denture was broken and then lost. Intraoral and radiographic features of the patient before treatment are shown in Figures 1 and 2.

In the extraoral examination, the temporomandibular joint (TMJ), eyes, nose, and lips were normal; the face was symmetrical and oval. In the intraoral examination, missing teeth were 18, 27, 28, 38, 37, 36, 35, 34, 44, 45, 46, 47, 48; dental caries were 24, 25, 26; Porcelain Fused to Metal (PFM) fixed - fixed bridge were $17,16,15,14,13$; with attrition teeth in the anterior mandibular region, and redness of the gums in the anterior mandibular region. Dental calculus was slightly found in most of the anterior mandibular region, and occlusion was not stable. Overjet was $2 \mathrm{~mm}$ and overbite 2 $\mathrm{mm}$. Premolar and molar lower, left and right vestibulum was shallow; with ovoid incisive shape; low buccal and high lingual frenulum; right and left mandibular flat ridge; ridge relation with transversal plane $\geq 800$; normal front; flat mandibular torus and palatinus torus; exostosis was not presented; right and left retromylohyoid were deep.

In the radiographic examination; there were radiopaque findings in the root canal of 26; and in the crown of 13 , $14,15,16,17$. Based on the above, the clinical diagnosis was confirmed: missing teeth were $36,35,34,44,45$, 46, 47; reversible pulpitis on $24,25,33,32,31,41,42,43$;
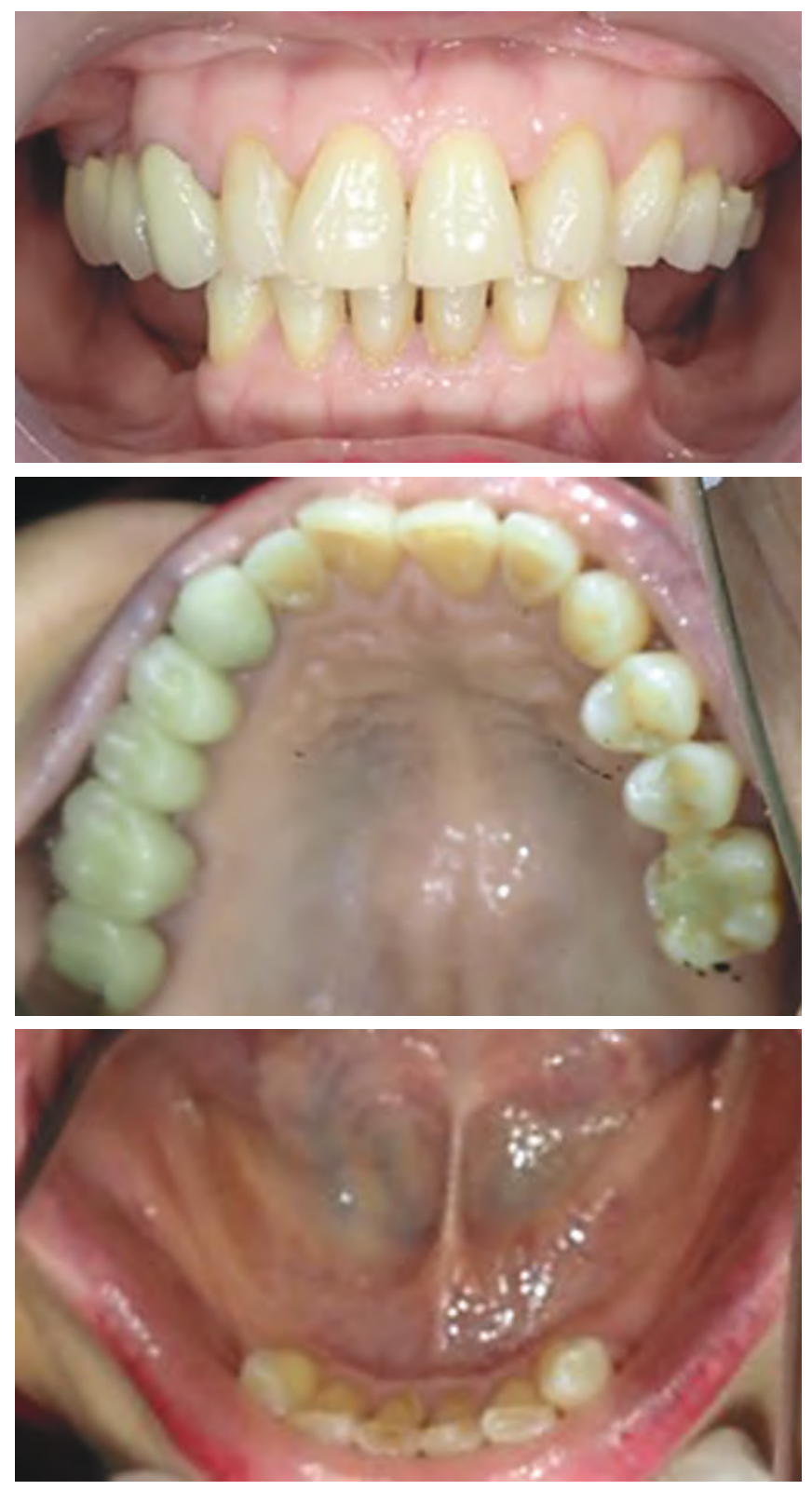

Figure 1. Pre-operative patient's intraoral examination.

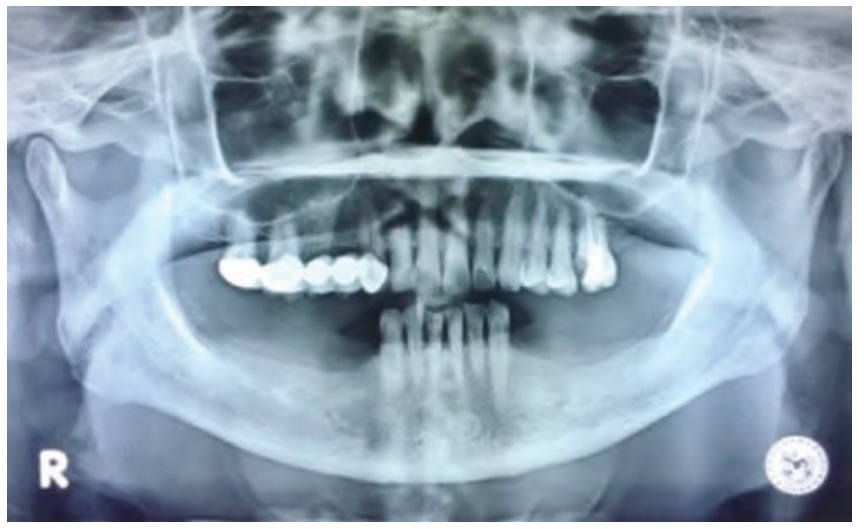

Figure 2. Pre-operative radiograph. 

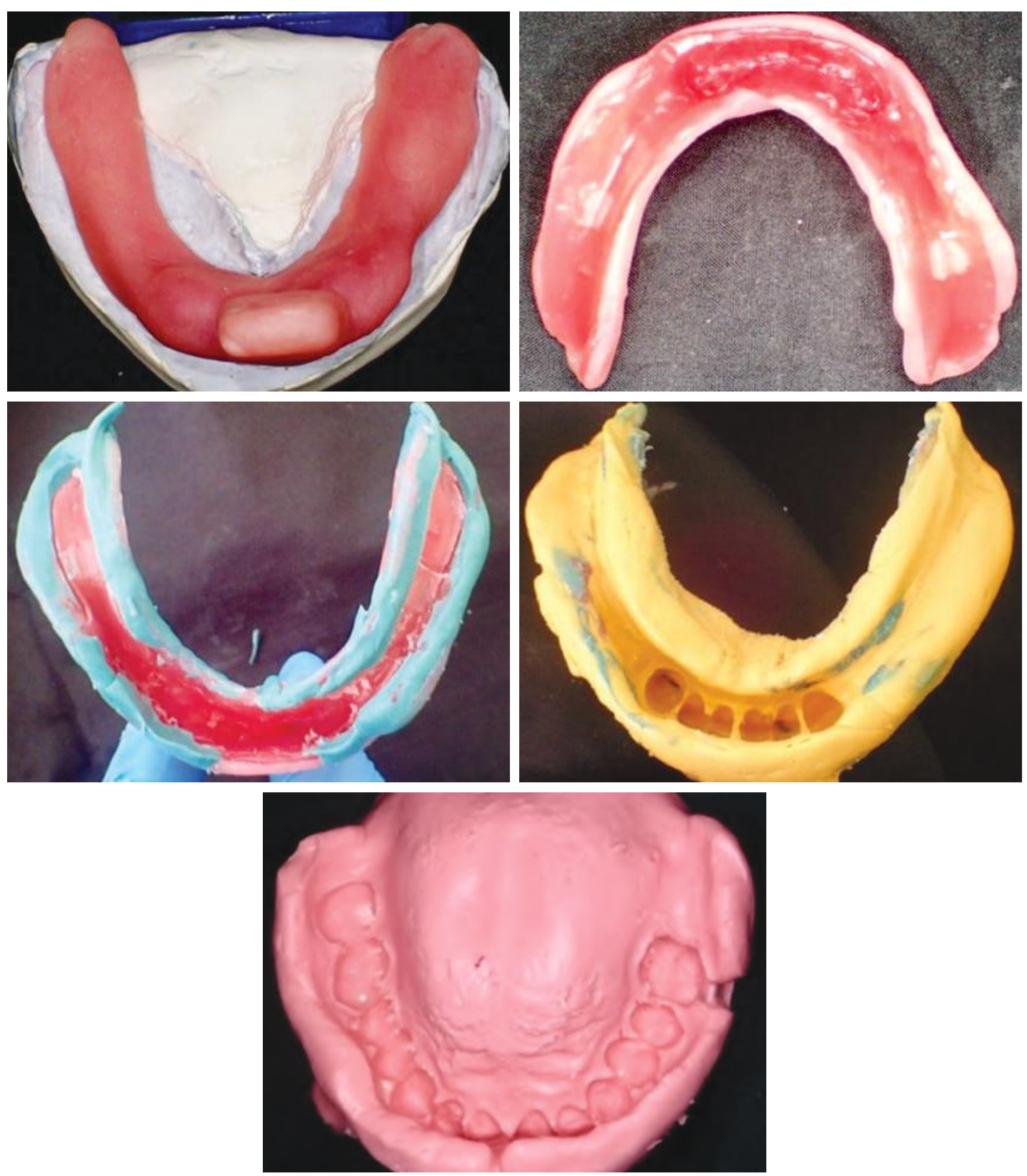

Figure 3. Individual tray, border molding, and mandibular functional impression.

pulp necrosis on 26; and chronic marginalis gingivitis. In this case, the mandibular transitional denture and bilateral mandibular attachment with retained removable partial denture were chosen to rehabilitate bilateral mandibular posterior edentulous for unstable occlusion patient.

In the transitional denture, Gillet clasp was used on 33 and 43; plate elevation on 33, 32, 31, 41, 42, 43; acrylic teeth and base were used. Whereas in the attachment, crown PFM were on 33 and 43; ball attachment were on 34 and 44; indirect composite teeth on 34 and 44; lingual plate were on $31,32,41,42$; acrylic teeth were used on $36,35,45,46,47$; metal base were used.
In this case, the transitional denture was planned to rehabilitate the unstable occlusion. The initial treatment was done through removing dental calculus; and direct restoration on $24,25,26,33,32,31,41,42$, and 43 . First, an individual tray was made to impress the edentulous ridge of the lower jaw. After the individual tray fits, the border molding was done with open mouth technique. The tray in the wax was removed and a mandibular functional model was made (Figure 3). Then the mold was cast using type 4 dental stone, and the antagonist mold was cast using type 3 dental stone (Figure 4). After this, the preparation of bite rim for bite determination was done (Figure 5). 

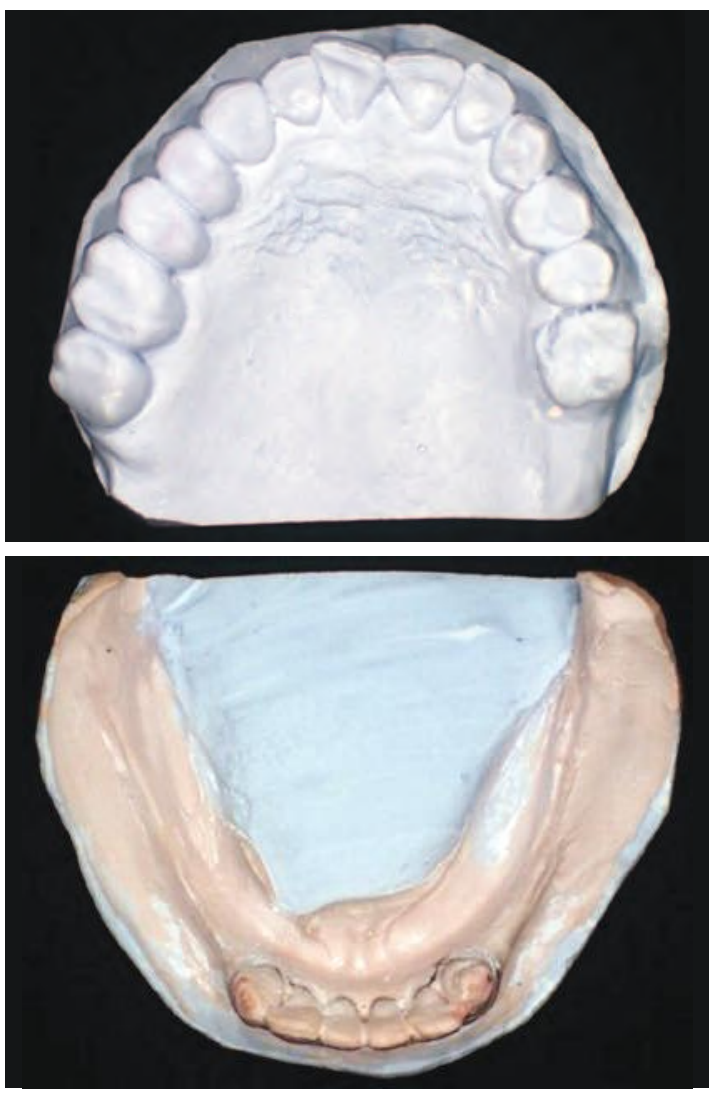

Figure 4. Cast model.

Before bite determination, the patient was previously trained to open and close her mouth to achieve appropriate occlusion. Bimanual manipulation technique was used to get the centric orientation of the patient. After determining the bite, the model was planted on the articulator. Posterior teeth were arranged and tried in the wax model of the patient (Figure 6).

Assessment was carried out to determine whether the conditions and occlusion were appropriate for the patient. After finishing and polishing, the transitional denture was adjusted to the patient's mouth. Assessment was carried out for function, occlusion, stability, and the occurrence of pain (Figure 7). After 3 months of follow-up, the patient's occlusion was stable and the patient was ready for bilateral mandibular attachment of the retained removable denture. After 3 months of use of the transitional denture, the patient complained of unfavorable aesthetics because the clasp of the denture was observable.

Dental preparation for teeth 33, 43 using fissure, tapered, and football-shaped diamond bur with a depth of $1.5 \mathrm{~mm}$ was done. Then the preparation suffix is chamfer (Figure 8). The impression of the maxilla and mandible was then performed. After the material was set, the mold was removed from the patient's mouth. The bite registration was then carried out using transitional denture. Temporary crown was inserted on 33 and 43 (Figure 9).
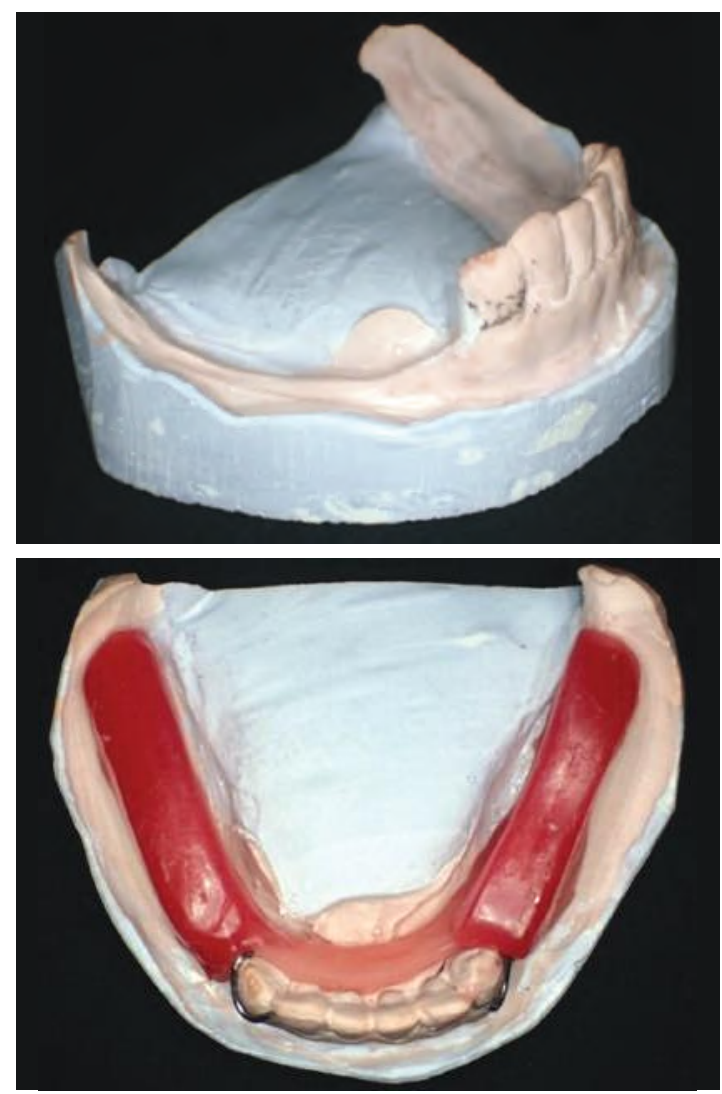

Figure 5. Survey, block out, and wax for bite determination.

The working model of the maxilla and mandible was planted to the articulator by bite registration and transitional denture. Metal coping was then made in the laboratory (Figure 10). The metal coping was tried to evaluate the cervical border and then returned to the laboratory for the porcelain coat (Figure 11).

The finished crown was tried by the patient for evaluation of cervical bound, anatomy, and color (Figure 12). Functional Impression II was done with double impression while the muscle trimming was performed with the splint crown at 33 and 43 installed on the patient, so that accurate impression was obtained. After obtaining the working model II, the articulator was replanted. Then, the model was sent to the laboratory for the mandibular metal frame. The wax denture was tried to see the compatibility of the arrangement, shape and color of the teeth of the mandible before the acrylic process was performed (Figure 13).

The final contour was followed by acrylic packing. Splint crown insertions at 31 and 41 were accompanied by bilateral mandibular attachment of the retained removable partial denture (Figure 14). The patient was taught how to remove and install the denture. Figure 15 showed intraoral examination of the patient before and after the insertion. 

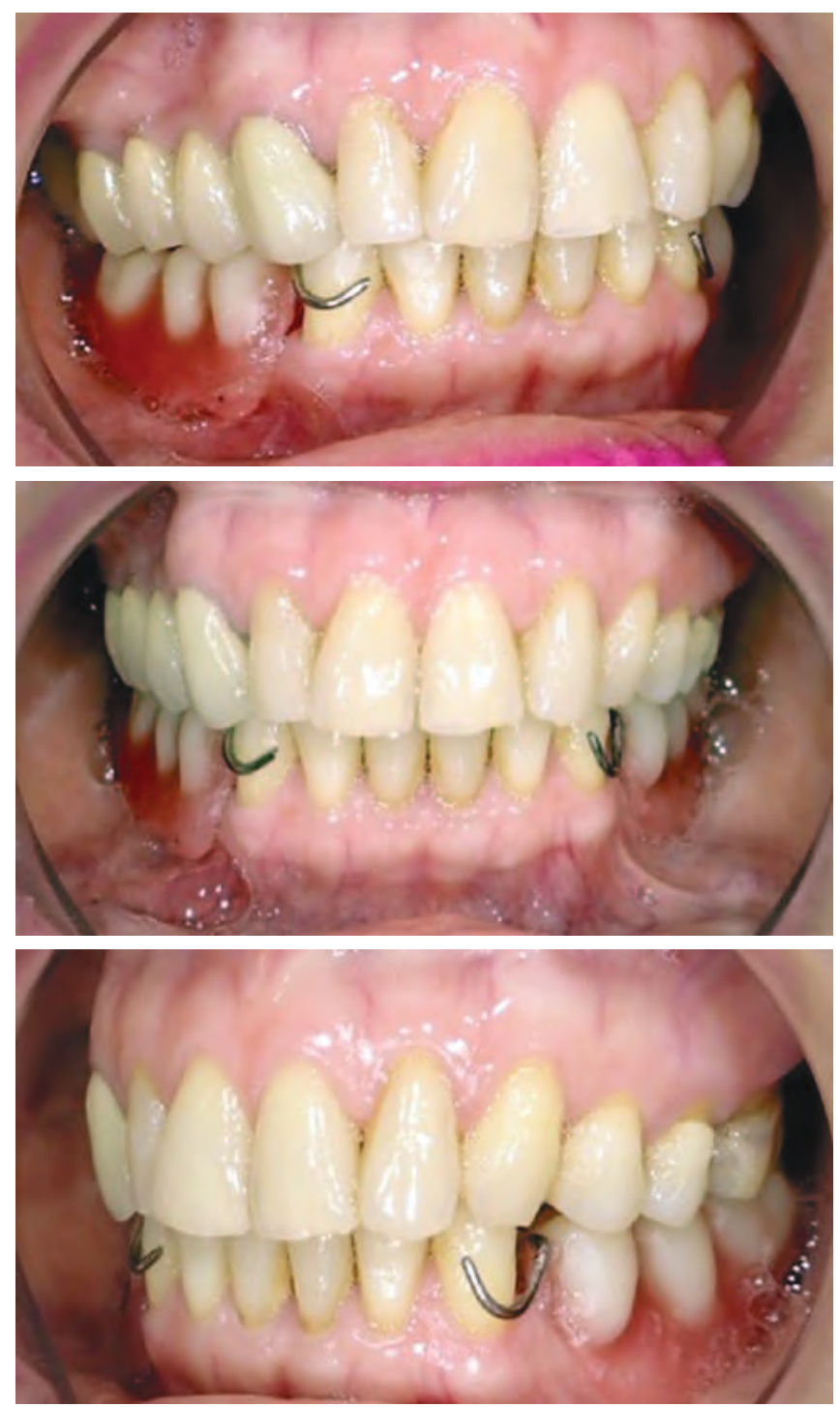

Figure 6. Wax try-in.

During the first 24 hours, the patient was advised not to use the denture for eating but only for adaptation and it must be used during sleep. The patient was advised to have 3 regular control visits, namely: control I (one day after insertion), control II (3 days after insertion), control III (7 days after insertion).

Control visit I: no complaints were presented; on intraoral examination, no lesions were found during the use of the denture; the patient felt satisfied with a new aesthetic appearance. Moreover, the aesthetic expectation of the patient was fulfilled.

Control visit II: there was no complaint; the stability was determined on the intraoral examination where no lesions were found during the use of the prosthesis, the patient felt satisfied with a new aesthetic appearance. Patient was directed to eat soft foods and have the next control visit to the dentist.
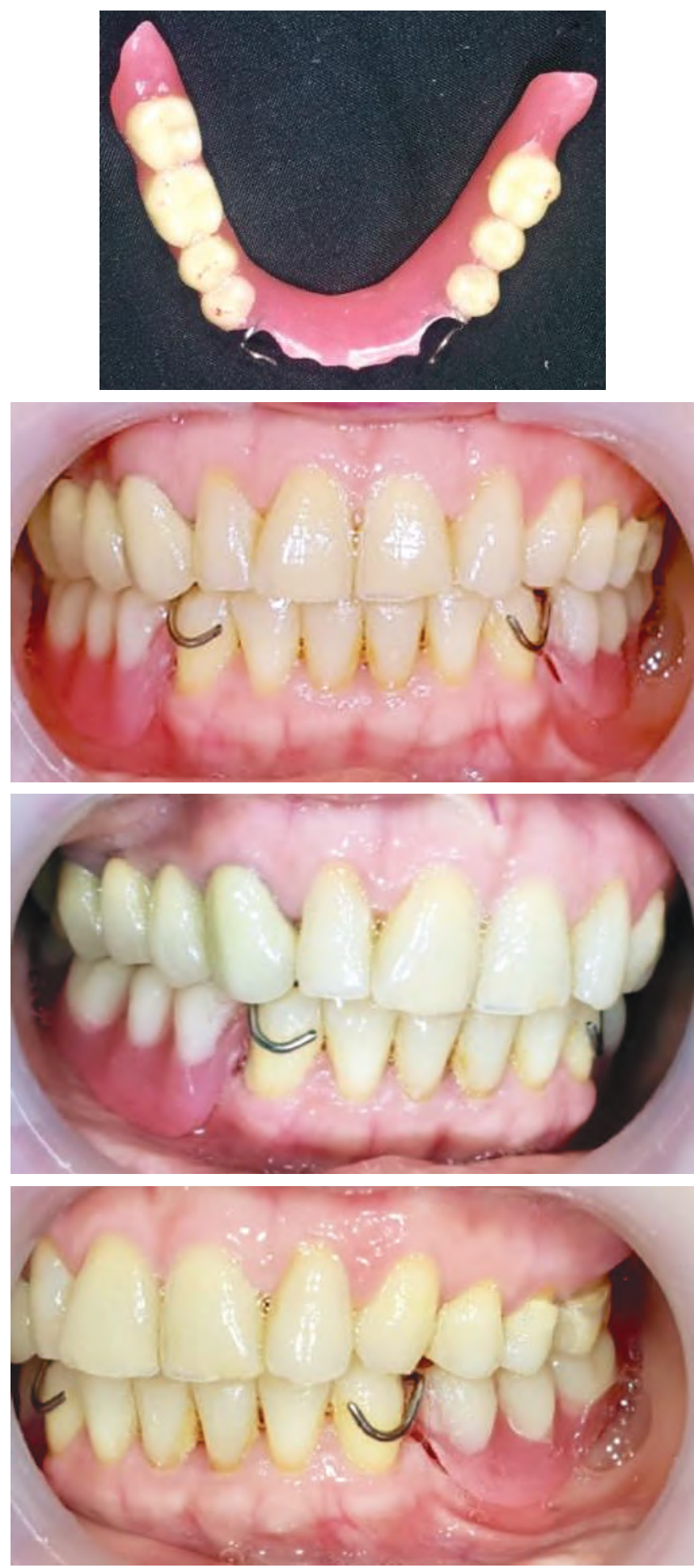

Figure 7. Transitional denture and insertion.

Control visit III: no complaints to pain or other inconvenience; on intraoral examination, there were no lesions seen in the tissue under the denture. Aesthetics, occlusion, articulation, and phonetics were good. Patient was directed to have routine control visits every 6 months (follow-up). 

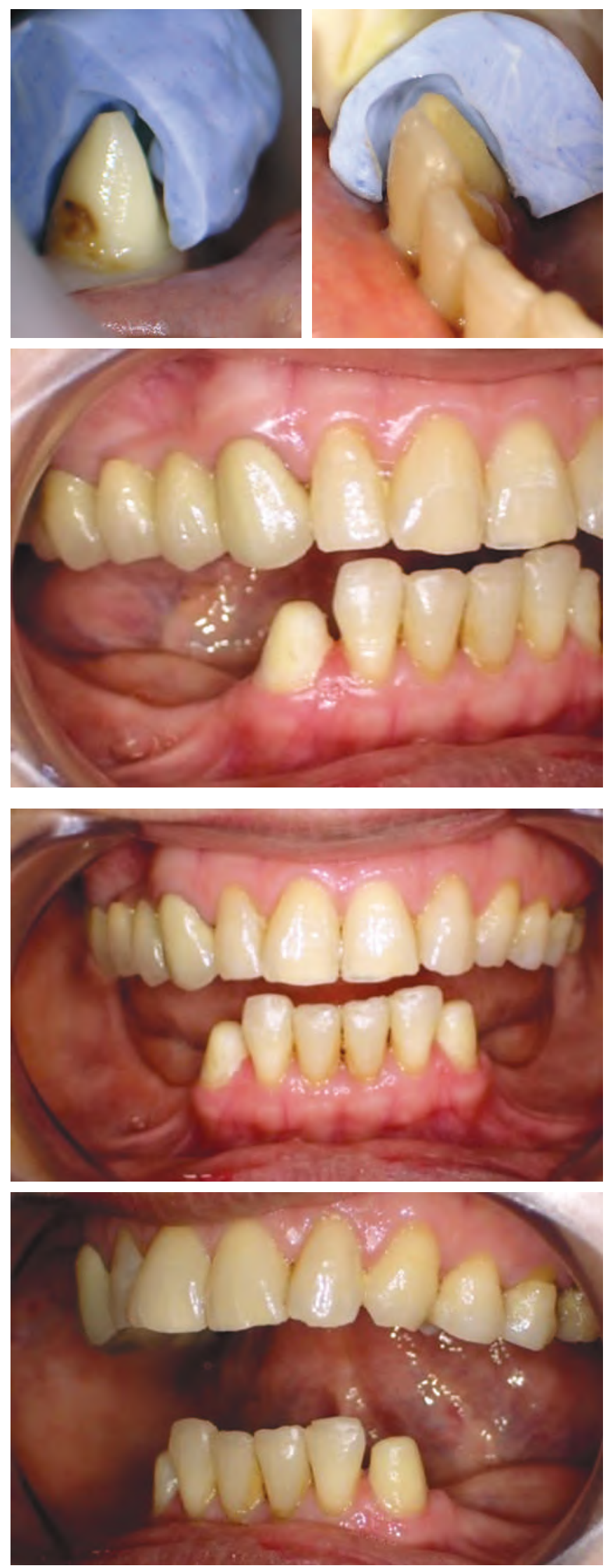

Figure 8. Preparation for crown abutment.
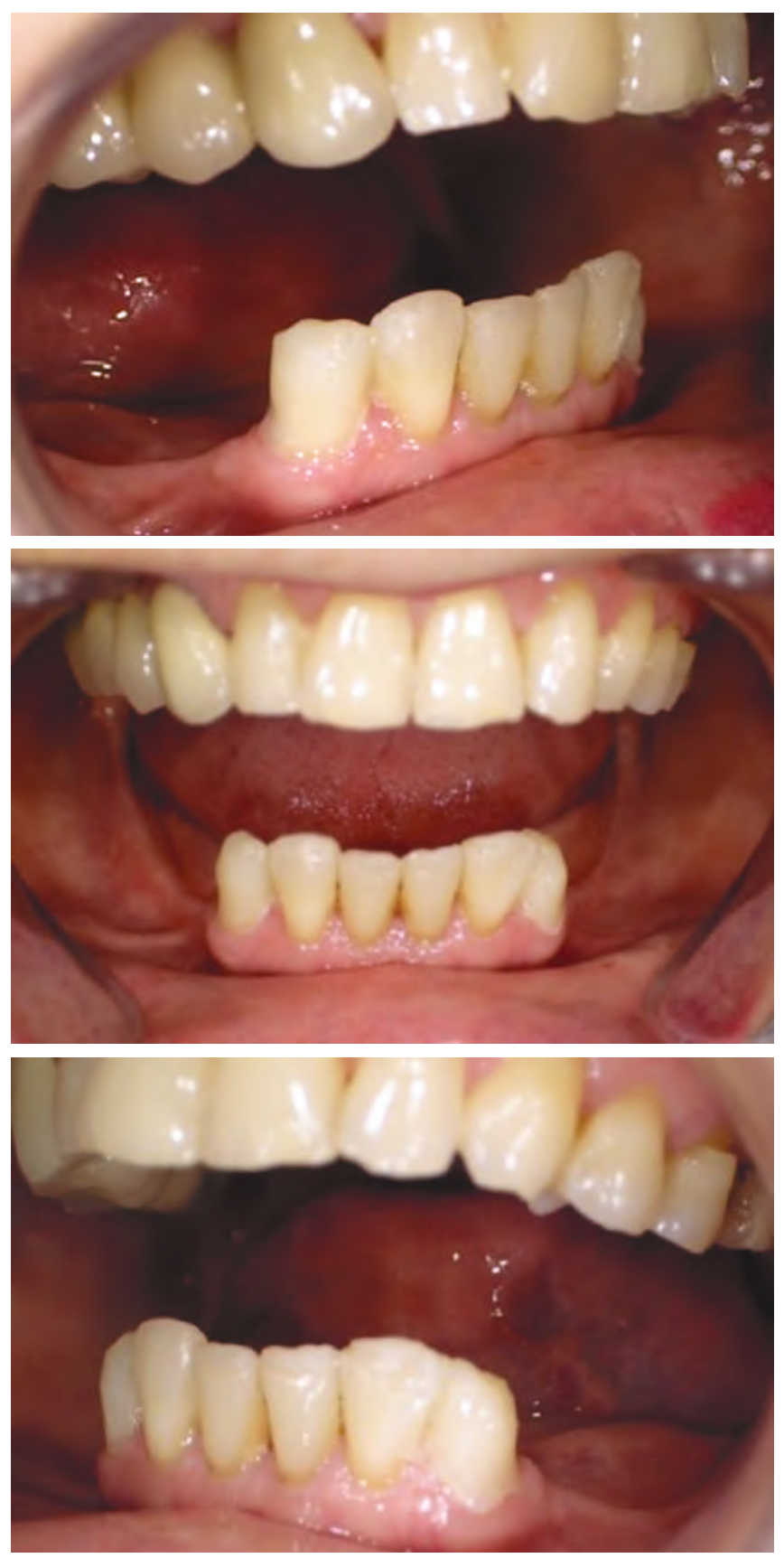

Figure 9. Temporary crown insertion.

\section{DISCUSSION}

Despite advances in preventive dentistry, edentulous is a major public health problem throughout the world. Edentulous is a debilitating and irreparable condition and is illustrated as "the ultimate marker of the burden of disease for oral health." One of the most important indices of oral health is the ability to integrally maintain teeth as long as life. ${ }^{6}$

The study determined that in the case of the absence of posterior teeth, it may be that degenerative alteration and 

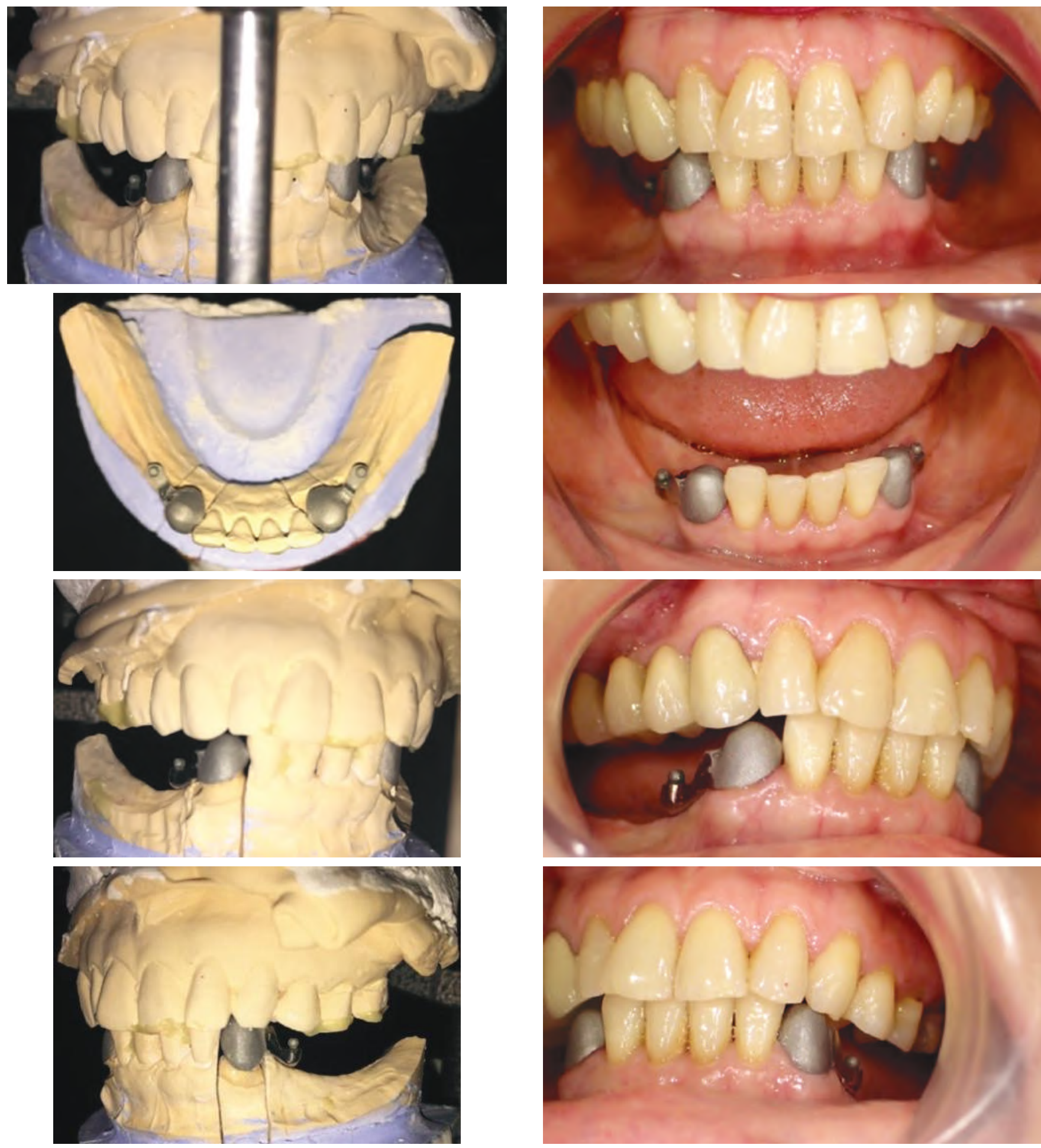

Figure 10. Preparation of model and metal coping.

the development of temporomandibular dysfunction had increased. The lack of occlusal strength and mastication, which was previously carried by the teeth, resulted to deterioration of tissue homeostasis, ending with the escalation of the possibility of developing Temporo Mandibular Disorder (TMD), as well as abnormal masticatory function. ${ }^{7}$

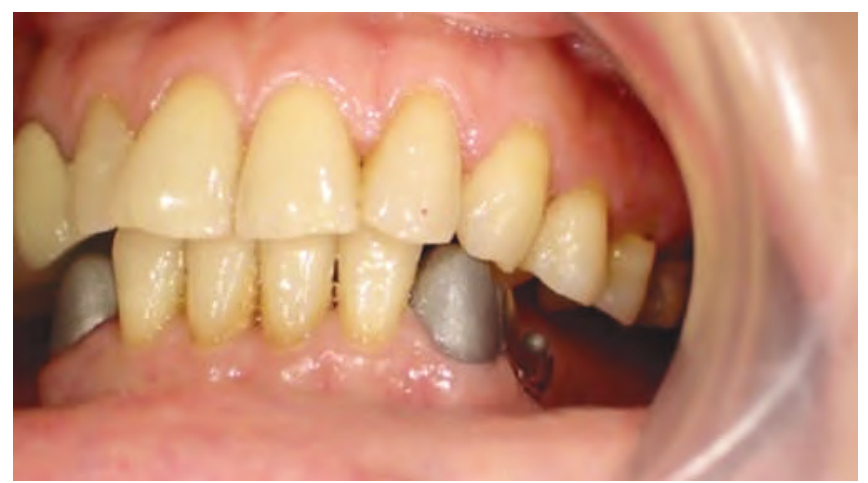

Figure 11. Try-in metal coping.

In this case, the patient's loss of bilateral mandibular posterior teeth may lead to unstable occlusion. In cases of loss of posterior teeth where patient occlusion changes when used for functional chewing, patients tend to advance the mandible forward to reach the occlusion position. There was unstable occlusion in this case because of loss 

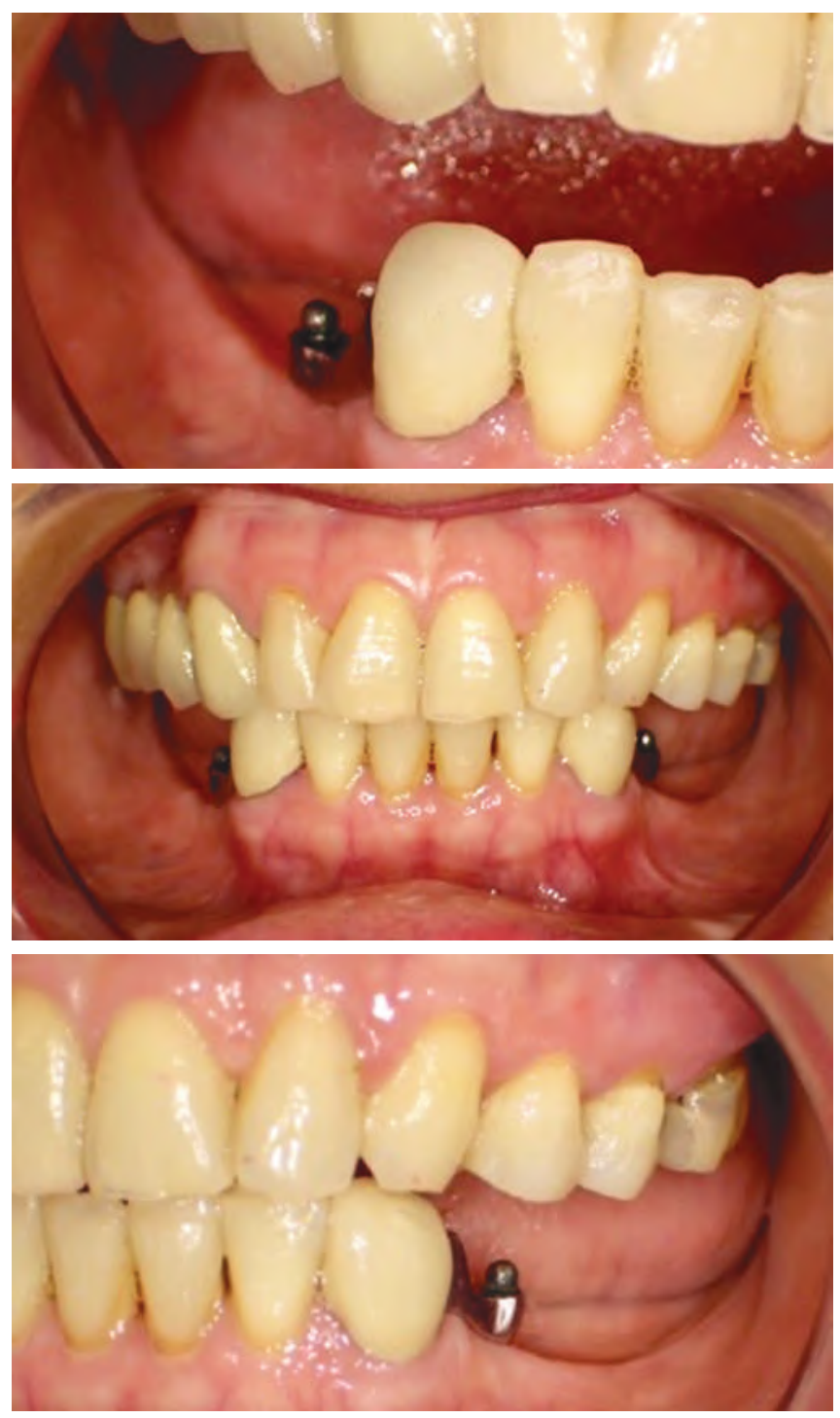

Figure 12. Try-in crown with porcelain.

of a guide posterior contact of occlusion where there was posterior mandibular rotation with an anterior rotation center located on the more anterior teeth. Change in occlusion may cause a joint disorder but in this patient, after the examination, there was no abnormality found. The use of transitional denture in the management of patients with unstable occlusion maintains the vertical dimension of occlusion with considerable inter-arch size; there is also adaptation of the condyle position to the most stable musculoskeletal position. Furthermore, the temporary design uses a Gillet clasp and plate elevation in the anterior teeth to divide the burden between the tooth and mucosa.

An attachment is a precision connector consisting of two or more parts. One part is connected to the roots, teeth, or implants. Other parts are connected to artificial prosthesis and are made to provide a mechanical connection between the two. Preparation design on suffix is chamfer,
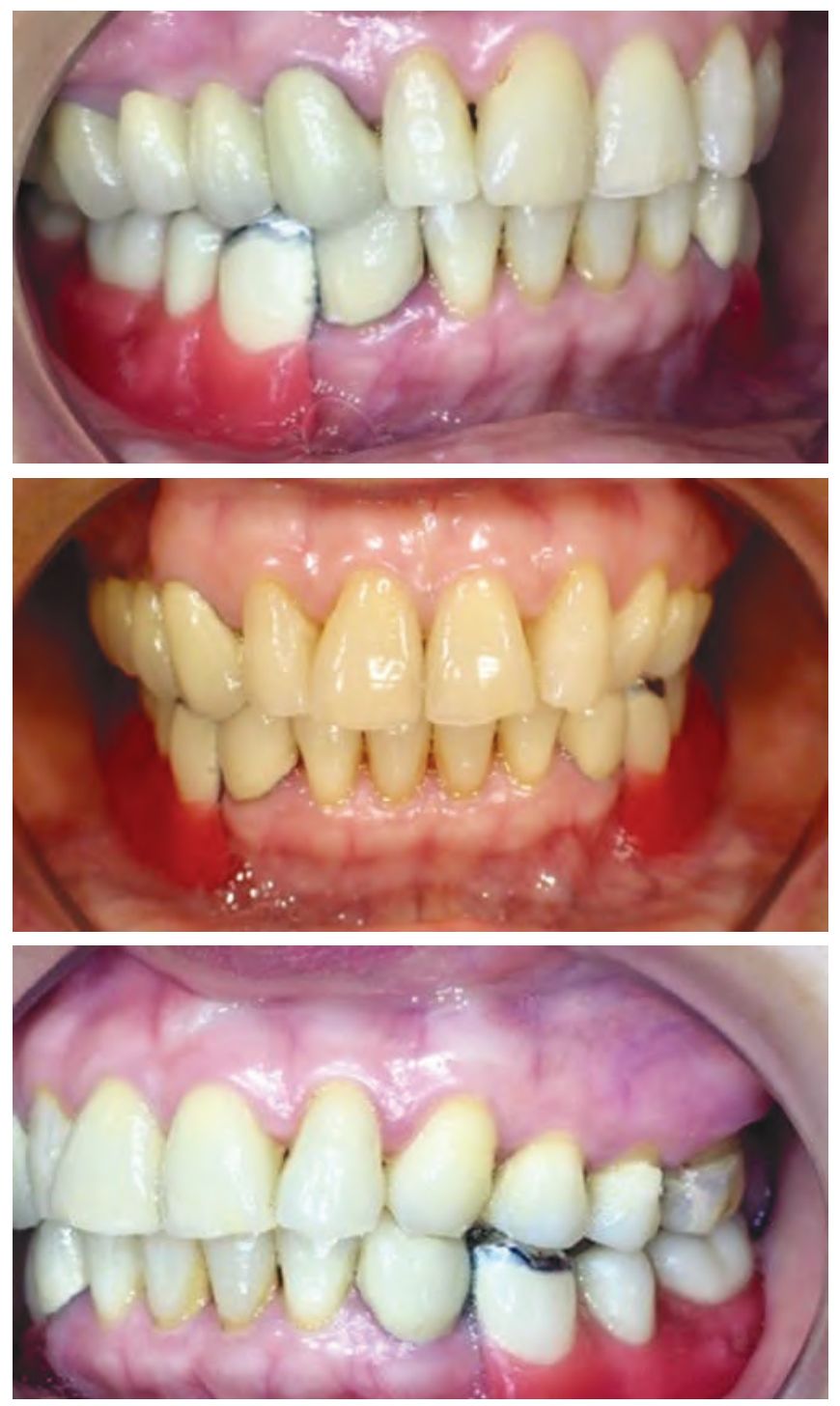

Figure 13. Try-in wax with posterior teeth.

which is the most suitable use for well - fitting metal casting with a high degree of precision in the margin preparation. ${ }^{8}$

Precision attachments offer the following additional advantages: valuable aesthetic features; standard interchangeable elements; controlled wear; and ease of repair. Indications for precision attachments include: fixed bridgework - intracoronal attachments on nonparallel abutments; partial dentures; overdentures; unilateral or bilateral free-end dentures. ${ }^{9}$ In this case, the patient had a high aesthetic expectation and loss of bilateral mandibular posterior teeth, therefore precision attachment was one of the most appropriate forms of treatment offered.

The forms of precision attachment include radicular stud; bars; intracoronal; and extracoronal attachments The radicular stud needs maximum length, post consistent with the length of the root, and a preparation at gum level to keep the fulcrum point low. The bars attachment used 

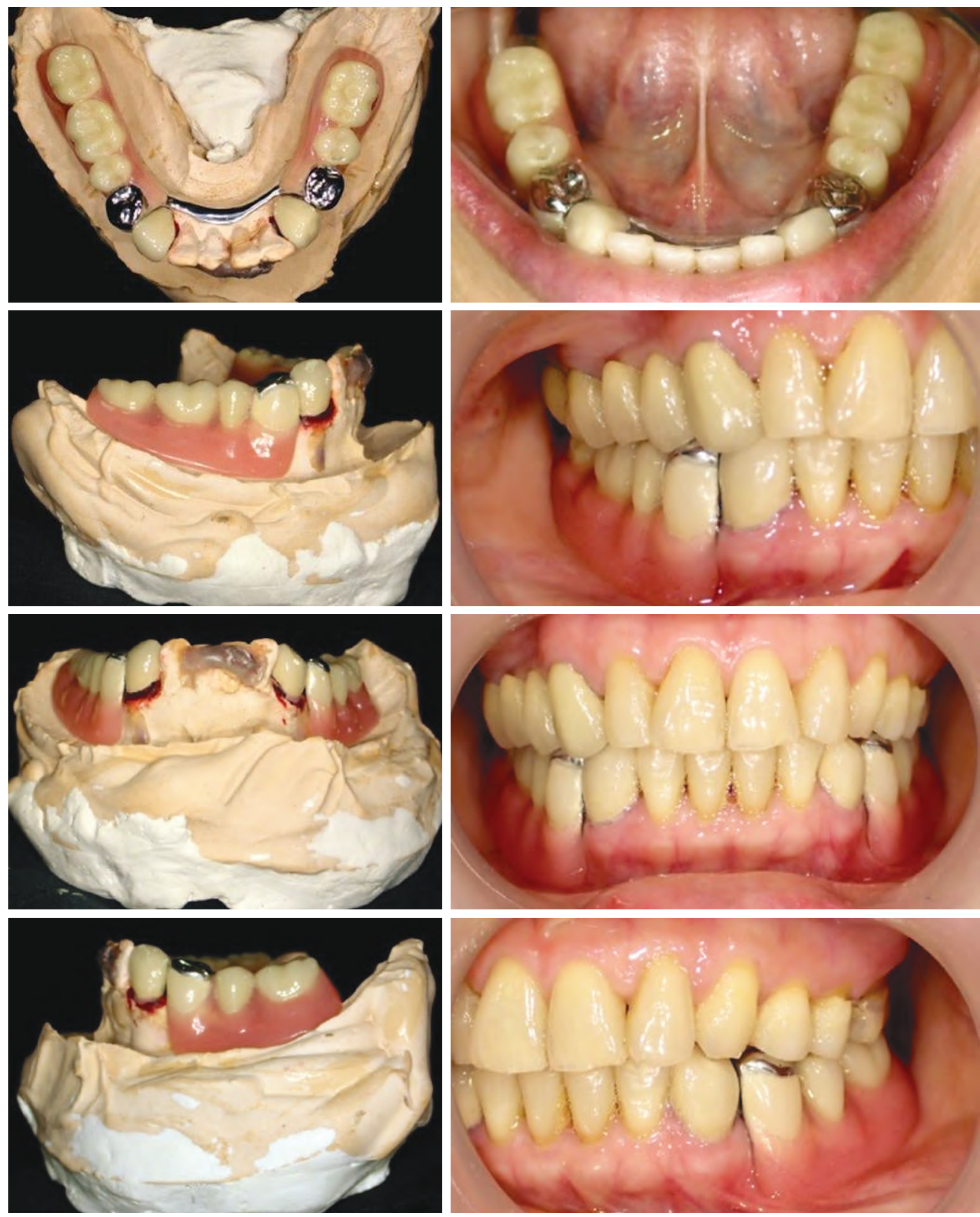

Figure 14. Retention of bilateral mandibular attachment and preparation and insertion of removable partial denture. 

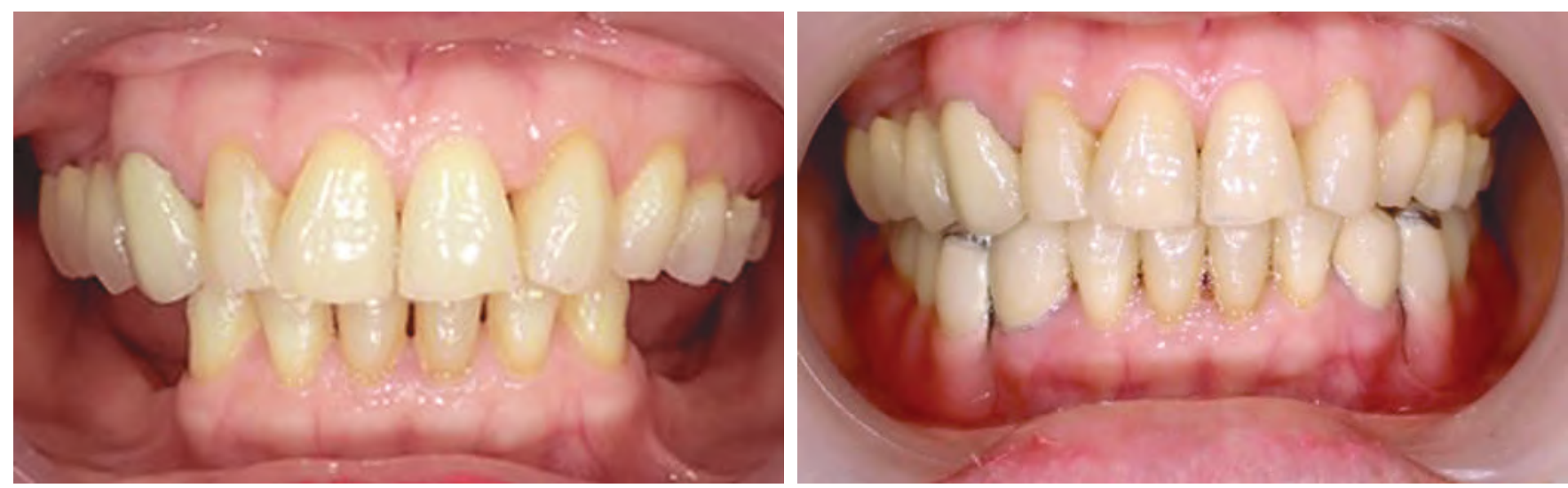

Figure 15. Patient's intraoral examination before and after insertion.

in small cross section allows for use in very close bites. The intracoronal attachment is made to accept an attachment within the circumference of the coronal surface. On the other hand, the extracoronal attachment is a conventional abutment preparation, which allows for an attachment to be situated outside the coronal circumference of the tooth. The preparation walls are near parallel sides to maximize retention of the crown; this type of attachment is more minimally invasive than the other types of attachments. In this case, extracoronal ball attachment was used; this form of attachment resulted in the success of laboratory support and careful clinical assessment of form and supportive occlusion.

The designs of precision attachment based on load distribution include resilient type and rigid type. In rigid type attachment, the load is carried by the tooth only and the requirement of good periodontal support from abutment is strictly needed. In resilient type, the load is carried by the mucosal support on residual ridge. This case used a resilient type attachment with abutment in 33 and 43 only. The method was innovative as the load distribution between the abutment teeth as well as the resilience of both the tissue overlooking the residual edentulous ridge was balanced because the transfixation on the fixed metal's lingual rim was not rigid. Furthermore, its resilience as a system provides stress relief because significant axis of the attachment is permitted, thereby decreasing the load focused on both the Removable Partial Denture (RPD) and teeth and making it suitable for patients with insufficient periodontal status. ${ }^{10}$

Vital or nonvital teeth can be used for abutment in attachment. However, research shows that the loss of attachment in nonvital teeth has increased significantly over time as opposed with vital teeth. The case report also found that somehow the abutment mobility of the teeth and bone height in the first group with vital abutment was lower than the nonvital teeth. Loading levels in nonvital teeth were twice that of vital teeth. ${ }^{11}$ Based on the considerations above, abutment teeth selected in vital tooth and as much as possible maintain its vitality by not taking too much hard tissue and careful in making preparations.
The life expectancy of an attachment if used well (well- functioning depends on the ability of the patient to perform post insertion maintenance) is, normally seven to ten years, sometimes longer. Patients with attachment denture should be educated about hygiene of the oral cavity and cleaning of the dentures. Denture attachment cleaning must be done after each meal. Patients are not allowed to use abrasive toothpaste. Patients are encouraged to remove the denture at bedtime, which is an efficient way to limit periodontal disease. For denture maintenance, the patient can use an antibacterial denture wash. The denture is applied first with liquid soap before the denture cleaning fluid is applied. When cleaning dentures, the use of toothpaste is avoided because most of them contain abrasive ingredients which can erode the acrylic resin field. ${ }^{12}$ Patients are advised to visit the dentist every 6 months and replace the attachment rubber once every two years or every retention decreases.

\section{CONCLUSION}

A denture that is supported by precision attachments produces greater satisfaction, improved aesthetic appearance, and good mastication. Use of non-clasp retention attachments makes for better aesthetics, rehabilitation, proprioception and satisfaction, and also provides retention, ease, and regularity of use of dentures. The technical procedure is simple and useful for patients with high aesthetic expectations.

\section{Statement of Authorship}

All authors participated in data collection and analysis, and approved the final version submitted.

\section{Author Disclosure}

All authors declared no conflict of interest.

\section{Funding Source}

None. 


\section{REFERENCES}

1. Akinboboye BO, Sulaiman AO, Bamgboye SA, Akeredolu PA, Dosumu OO. Impact of Tooth Loss on Individuals with Unrestored Partially Edentulous Arch in Southwestern Nigeria - A Preliminary Survey. Afr J Biomed Res. 2016; 19(2):149-53.

2. DuPont G. 5 Requirements for Occlusal Stability. Dawson Academy. 2013;1-2.

3. Volchansky A, Cleaton - Jones P, WG E, Shackleton J. Patterns of Previous Tooth Loss in Patients Presenting at Five Different Types of Dental Practice. SADJ. 2016;71:70-4.

4. Cesto FM, Domareski L, Samra APB, Neppelenbroek KH, Campanha $\mathrm{NH}$, Urban VM. Overlay removable partial denture as temporary restoration of vertical dimension of occlusion in a bruxist patient. Rev Gauch Odontol. 2015;63(1):95-102.

5. Olcay S. Removable Partial Dentures. Switzerland: Springer International Publishing; 2016. pp.171-194.

6. Vadavadagi SV, Srinivasa H, Goutham GB, Hajira N, Lahari M, Reddy GTP. Partial Edentulism and Its Association with Socio-Demographic Variables among Subjects Attending Dental Teaching Institutions, India. J Int Oral Health. 2015;7(Suppl 2):60-3.
7. Malheiros AS, Carvalhal ST, Pereira TL, Filho EM, Tonetto MR, Goncalves LM, et al. Association between Tooth Loss and Degree of Temporomandibular Disorders: A Comparative Study. J Contemp Dent Pract. 2016;17(3):235-9.

8. Shillingburg HT, Sather Jr DA, Wilson Jr EL, Cain JR, Mitchell DL, Blanco LJ, Kessler JC. Fundamentals of Fixed Prosthodontics Fourth Edition. Bateman LA, ed. Carol Stream: Quintessence Publishing Co, Inc; 2012. pp. 128-129.

9. Bartlett DW. Clinical Problem Solving in Prosthodontics. London: Elsevier Health Sciences; 2003. pp.11-17.

10. Schuh C, Adiel Skupien J, Mesko ME, Valentini F, Pereira - Cenci T, Boscato N. Resilient Attachments as an Alternative to Conventional Cast Clasp Removable Partial Denture : 3-Year Follow-up. J Indian Prosthodont Soc. 2014; 14(Suppl 1):273-8.

11. Arafa KO. Effect of the vitality of the overdenture abutment tooth on stability of the tooth. Saudi J Oral Sci. 2016; 3(1):17-20.

12. Hong L, Ettinger RL, Watkins CA, Wefel JS. In vitro evaluation of fluoride varnish on overdenture abutments. J Prosthet Dent. 2003;89(1):28-36.

\section{The Acta Medica Philippina is now accepting limited advertising for its front and back cover (colored), as well as for available spaces in some of its pages, as appropriate. For inquiries and submission of proposals, please email us at actamedicaphilippina.upm@up.edu.ph}

